\title{
Comunicação, mobilização social e cidadania: aprendendo com a vigilância cívica do terceiro setor
}

Communication, social mobilization and citizenship:

learning from the civic surveillance of the third sector

Comunicación, movilización social y ciudadanía:

aprendiendo con la vigilancia cívica del tercer sector

Wilson da Costa Bueno

- Doutor e mestre em Ciências da Comunicação pela Escola de Comunicações e Artes da Universidade de São Paulo (ECA-USP)

- Graduado em Jornalismo pela ECA-USP

- Especialista em Comunicação Rural pela ECA-USP

- Professor do Programa de Pós-Graduação em Comunicação da Universidade Metodista de São Paulo (Umesp)

- Líder do grupo de pesquisa Comunicação Empresarial no Brasil: uma leitura crítica (Criticom)

- Diretor da Comtexto Comunicação e Pesquisa e da Mojoara Editorial

- E-mail: professor@comtexto.com.br 


\section{Resumo}

A comunicação comunitária desempenha papel fundamental no processo de autoemancipação dos movimentos populares, contribuindo para incrementar a sua autonomia e a sua visibilidade. As organizações do terceiro setor elaboram projetos, utilizam canais e discursos que têm estimulado o debate sobre direitos humanos, sustentabilidade e liberdade de expressão, entre outros temas atuais e relevantes. Neste artigo, descrevemos e analisamos as estratégias comunicacionais de dois de seus mais destacados representantes: o Movimento dos Atingidos por Barragens (MAB) e o Greenpeace.

\section{PALAVRAS-CHAVE: MOBILIZAÇÃO SOCIAL・TERCEIRO SETOR・COMUNICAÇÃO COMUNITÁRIA・CIDADANIA.}

\section{Abstract}

Community communication plays a fundamental role in the self-emancipation process of popular movements, contributing to increase their autonomy and visibility. Third sector organizations design projects, use channels and speeches that have been stimulating the debate about human rights, sustainability and freedom of expression, among other current and relevant topics. In this article, we describe and analyze the communication strategies of two of their most prominent representatives: the Movimento dos Atingidos por Barragens (MAB) (Movement of People Affected by Dams) and the Greenpeace.

\section{KEYWORDS: SOCIAL MOBILIZATION・THIRD SECTOR・COMMUNITY COMMUNICATION・CITIZENSHIP.}

\section{Resumen}

La comunicación comunitaria juega un papel clave en la auto-emancipación de los movimientos populares, contribuyendo para aumentar su autonomía y visibilidad. Las organizaciones del tercer sector elaboran proyectos, utilizan canales de comunicación y discursos que han estimulado el debate sobre los derechos humanos, la sostenibilidad y la libertad de expresión, entre otros temas actuales y relevantes. En este artículo, se describen y analizan las estrategias de comunicación de dos de sus representantes más prominentes: MAB - Movimento dos Atingidos por Barragens (Movimiento de las Personas Afectadas por las Represas) y Greenpeace. 
números países, como o Brasil, têm encontrado dificuldades, aparentemente incontornáveis, para reduzir as desigualdades em suas várias dimensões (raciais, de gênero, educacionais, econômicas etc.), promover a justiça e a inclusão social, trilhar os caminhos da sustentabilidade e eliminar os privilégios que consolidam e legitimam a hegemonia das classes mais favorecidas.

A inexistência, em nosso país, de políticas públicas eficazes para superar esse desafio, aliada à corrupção que contamina, de forma significativa, a nossa classe política e empresarial e à falta de comprometimento com o interesse público, tem exigido a participação crescente de entidades da sociedade civil e, em particular, dos movimentos sociais, com objetivo de realizar as transformações necessárias para alterar esse cenário.

0 consumismo se define como ideologia dominante e o PIB se institui como o indicador mais importante, ainda que precário e inadequado, para caracterizar o nosso grau de desenvolvimento. Os lobbies empresariais, respaldados em competentes, mas nem sempre éticas, ações ou estratégias comunicacionais, têm conseguido, com a cumplicidade e/ou a complacência dos governos, fazer prevalecer os seus interesses, relegando a um segundo plano os anseios da população brasileira ou de segmentos que a representam.

\section{REVISANDO CONCEITOS}

Ainda que não seja objetivo deste texto a discussão abrangente de conceitos que, implícita ou explicitamente, integram a nossa argumentação, estaremos examinando alguns deles, como os de mobilização social, comunidade, comunicação comunitária e terceiro setor, valendo-nos do esforço já empreendido por outros autores que, ao longo do tempo, têm se ocupado de sua elaboração.

Admitimos, aqui, mobilização social como um esforço coletivo e planejado no sentido de resolver um problema, concretizar uma ação (ou até mesmo impedir que uma ação ou proposta se realize) com o intuito de angariar benefícios ou vantagens para aqueles que o empreendem. Explicam Henriques, Braga e Mafra Henriques (2003, p. 3):

Mobilizar, portanto, é convocar estas vontades de pessoas que vivem no meio social (e optaram por um sistema político democrático) para que as coisas funcionem bem e para todos; é mostrar o problema, compartilhá-lo, distribuí-lo, para que assim as pessoas se sintam corresponsáveis por ele e passem a agir na tentativa de solucioná-lo.

Evidentemente, a mobilização social não representa uma tarefa simples e depende de uma série de condições para que efetivamente aconteça. Fazer convergir dentro de um grupo (ou público) uma decisão que represente a vontade da maioria é tarefa que exige, sobretudo, um nível desejável e democrático de participação dos seus integrantes, porque, apenas dessa forma, será possível a elaboração e a execução de uma ação ou estratégia.

Como o processo de mobilização social prevê, quase sempre, mudanças significativas no status quo, é razoável admitir que enfrentará resistências daqueles que não pretendem abrir mão de seus privilégios ou vantagens. Portanto, se não houver suficiente comprometimento e unidade de ação dos que buscam as mudanças, a mobilização social não alcançará os resultados esperados. Além disso, os representantes do(s) público(s) que promove(m) a mobilização, como indivíduos, têm percepções nem sempre uniformes do problema (e da sua solução), o que torna o processo efetivamente complexo.

O conceito de comunidade tem sido utilizado e debatido por inúmeros autores, em especial das áreas de ciências sociais/ sociologia e de comunicação, merecendo menção a professora e pesquisadora Cicília Peruzzo (2009), com valiosa 
contribuição ao estudo e à investigação da chamada comunicação comunitária, alternativa e popular. Ela recorre a Marcos Palácios (2001) para enumerar os elementos essenciais que identificam uma comunidade: os sentimentos de pertencimento e de comunidade, a permanência, a territorialidade e a forma específica de comunicação que vigora entre os membros da comunidade. A autora tem chamado a atenção para o fato de que a visão moderna e ampliada do conceito não restringe, como anteriormente, a territorialidade a uma localidade geograficamente definida.

Na verdade, é possível, como Peruzzo (2009, p.143-145) acentua, imaginar a territorialidade sob uma perspectiva simbólica e não físico-geográfica, visto que as pessoas podem agrupar-se, mesmo à distância, em função de interesses comuns, disposição que se viabiliza pela construção e expressão de uma identidade. A autora admite que

essas identidades podem nascer da intenção em manter o status quo ou de resistir aos processos dominantes e às efemeridades do mundo globalizado, ou ainda de buscar a transformação da estrutura social. Em todas elas existem processos de identidade, objetivos e interesses em comum, bem como a participação em prol desse objetivo e o sentimento de pertença, oriundo da identidade em questão (Peruzzo, 2009, p. 144).

A ampliação do conceito de comunidade, então, permite-nos abrigar dentro dele movimentos ou ações que não se prendem à noção de presença ou vivência meramente física e que, na contemporaneidade, se multiplicam em todo o mundo. Sob essa perspectiva meramente simbólica ou identitária, é possível imaginar comunidades constituídas de membros que se localizam em territórios ou locais geograficamente distantes.

0 terceiro setor designa o conjunto de entidades de natureza privada sem fins lucrativos e que, basicamente, se constituem, segundo o Código Civil Brasileiro (Lei 10.406, de 10 de janeiro de 2002)', em associações ou fundações. 0 artigo 53 dessa lei entende que associações representam a "união de pessoas que se organizam para fins não econômicos" e deixa explícito que há uma distinção importante entre associações e fundações.

As fundações, diferentemente das associações, constituem-se a partir de um patrimônio, ou seja, seu(s) instituidor(es) deverá(ão), "por escritura pública ou testamento, dotação especial de bens livres, especificando o fim a que se destina, e declarando, se quiser, a maneira de administrá-la" (artigo 62 do Código Civil). Tanto os indivíduos, quanto as empresas e 0 poder público, podem constituir fundações.

As associações podem incorporar algumas autodenominações específicas e, por isso, encontramos as ONGs (organizações não-governamentais), as OSCIPs (organizações da sociedade civil de interesse público), e ainda as instituições e as entidades. Cada uma dessas denominações tem as suas particularidades, que são assumidas pelas associações em função de seus objetivos e de sua estrutura. ${ }^{2}$

0 parágrafo único do artigo 62 da lei anteriormente citada explicita uma série de finalidades a serem cumpridas pelas fundações e elas deverão estar indicadas no momento da sua constituição.

1 Os artigos referentes às associações e fundações (artigos 53 a 69) encontram-se, respectivamente, nos capítulos II e III dessa lei, no endereço <http://www.planalto. gov.br/ccivil_03/leis/2002/L10406.htm>.

2 É possível encontrar informações que ajudam a identificar e a distinguir esses diferentes tipos de associações no Manual do terceiro setor, elaborado pelo Instituto Pro Bono, citado nas referências bibliográficas ao final deste artigo. 


\section{ANO 14 • NÚMERO 26 • 1은. 2017 • ORGANICOM \\ COMUNICAÇÃO, MOBILIZAÇÃO SOCIAL E CIDADANIA: APRENDENDO COM A VIGILÂNCIA CÍVICA DO TERCEIRO SETOR}

\section{COMUNICAÇÃO E VIGILÂNCIA CÍVICA}

A comunicação dita comunitária constitui-se em processo que se materializa pela ação das comunidades e que costuma ser identificada com os movimentos sociais e as organizações sem fins lucrativos, integrando o chamado terceiro setor. Ela é

desenvolvida de forma democrática por grupos populares em comunidades, bairros, espaços online etc., segundo seus interesses, necessidades e capacidades. É feita pela e para a comunidade. Portanto, se funda na participação ativa dos membros em todo 0 processo de praticar comunicação (Peruzzo, 2013, p. 13).

Muitas vezes, ela tem sido denominada "outra comunicação", seja pelo perfil singular de quem a protagoniza, como movimentos sociais, entidades que estão associadas à defesa de interesses específicos (direitos humanos, direitos das crianças e adolescentes, meio ambiente, trabalhadores rurais, indígenas, negros, mulheres etc.), seja pela apropriação de de canais ou veículos fundamentalmente distintos da chamada mídia tradicional, identificados com os interesses de classes ou grupos hegemônicos e que obedecem a um sistema de produção e administração essencialmente verticalizado.

Na comunicação comunitária, a produção não é, necessariamente, fruto do trabalho de profissionais (da comunicação), embora possa incorporá-los, mas o resultado de um esforço coletivo baseado na participação e na corresponsabilidade. Enquanto, na comunicação tradicional, os profissionais da comunicação (os jornalistas, por exemplo) estão sob a tutela de empresários ou editores, respondendo a estes ou obedecendo às suas determinações, na comunicação comunitária autêntica prevalece a construção coletiva de um discurso e de uma prática que estão alinhados com a posição que representa a totalidade (ou pelo menos a maioria) dos seus membros.

A prática e a ação da comunicação comunitária estão fundadas em determinados princípios ou valores, como a democracia e o pluralismo, a representatividade, a participação ativa, a autonomia, a consistência dos conteúdos produzidos e disseminados e essencialmente uma força motriz, empreendida para "ampliar o exercício dos direitos e dos deveres de cidadania com vistas à constituição de uma sociedade livre, justa e igualitária" (Peruzzo, 2009, p. 420).

A disposição democrática de participar, entendida a partir de uma decisão de caráter político, é central na comunicação comunitária (alternativa, popular) e se manifesta de forma contundente: "participar é partilhar, é interferir, é deixar der ser súdito e se reconhecer cidadão portador de direitos e deveres e agir como tal" (Peruzzo, 2009, p. 422).

Esse ânimo de modificar, promover mudanças, alterar o status quo provoca mudanças importantes no modus operandi da comunicação comunitária (e das relações públicas, de maneira geral). Quando essa disposição está presente, o fazer comunicação "passa a constituir-se a partir de demandas das próprias organizações de base popular, respeitando a dinâmica coletiva, pois o que interessa é democratizar o saber e a técnica, além de municiar o cidadão de capacidades que contribuam para sua autoemancipação" (Peruzzo, 2009, p. 426).

É importante salientar que a comunicação comunitária se realiza ainda que não inclua em sua práxis profissionais de comunicação (por exemplo, relações públicas), mesmo porque, no caso de associações de pequeno porte, nem sempre há recursos disponíveis para contratá-los. Mas é comum encontrarmos profissionais comprometidos com a comunicação comunitária e que emprestam uma participação espontânea para que ela se efetive, seja contribuindo para a capacitação em comunicação dos membros da comunidade, seja atuando diretamente no processo de mobilização social pela identificação com a causa, a "força motriz" das organizações ou dos movimentos sociais. 
Kunsch, a exemplo de Peruzzo (2009, 2013), define alguns princípios para caracterizar as relações públicas comunitárias, incluindo entre eles "a educação libertadora como norteadora das ações" e a valorização da "cidadania e da solidariedade humana" (Kunsch, 2009, p. 447).

A comunicação comunitária (popular, alternativa) é, essencialmente, uma comunicação mobilizadora, politicamente engajada no sentido mais abrangente da atuação política, que se confunde com o civismo e não com a prática partidária, que já incorpora, de per si, um ethos restritivo.

A comunicação comunitária autêntica é avessa a interferências externas ou apropriações moralmente condenáveis, e não é lícito utilizar o conceito de relações públicas comunitárias para expressar essas práticas.

\section{COMUNICAÇÃO COMUNITÁRIA EM MOVIMENTO: MAB E GREENPEACE}

Para ilustrar os conceitos que dão suporte a esta reflexão e explicitar algumas práticas de comunicação comunitária realizadas em nosso país, escolhemos duas associações (um movimento social e uma ONG) que trabalham ativamente a questão socioambiental: o Movimento dos Atingidos por Barragens (MAB) e o Greenpeace, uma organização nãogovernamental com atuação global, mas que também contempla o olhar local em dezenas de países nos quais está presente.

\section{Movimento dos Atingidos por Barragens (MAB)}

O Movimento dos Atingidos por Barragens (MAB) surgiu no final de década de 1970 para organizar e mobilizar os atingidos pela construção de barragens em nosso país, tendo em vista a defesa de seus direitos. Ele é resultado da mobilização de agricultores do Rio Grande do Sul e de Santa Catarina contra a construção de usinas hidroelétricas no Alto Uruguai, uma região fisiográfica formada por dez municípios gaúchos. A história do MAB está associada à atuação da Igreja, com participação decisiva de agentes pastorais da Igreja Católica e da Igreja Protestante de Confissão Luterana. A Comissão Pastoral da Terra (CPT) foi responsável, em 1979, pela criação da Comissão de Barragens para analisar o impacto das desapropriações de terras com a implantação de hidrelétricas no sul do país. Essa comissão, posteriormente, se desdobrou em comissões regionais que se aglutinaram no Movimento dos Atingidos por Barragens, na metade da década de 1980.

Maria JoséReis (2007), a relatar com detalhes a história do MAB, lembra que, na prática, este teve, no seu processo de consolidação, apoio importante de assessorias técnicas, o que imprimiu maior consistência ao seu funcionamento. A autora, no entanto, reconhece que o MAB evoluiu de "serviço" a movimento, com a gradativa conscientização de que o processo de mobilização só seria efetivo se assumisse uma perspectiva prática, transcendendo o universo simbólico decorrente da participação religiosa e a argumentação técnica, derivada do apoio das assessorias especializadas comprometidas com o movimento.

A principal reinvindicação do MABéa criação de uma política nacional que defina critérios precisos eabrangentes para a reparação de prejuízos causados às pessoas atingidas pelas barragens e que promova o reassentamento das famílias cadastradas. 0 movimento instituiu inclusive uma data (14 de março) como o dia internacional de luta contra as barragens e tem tido atuação destacada contra a implantação de empreendimentos energéticos na Amazônia, como a Usina Hidrelétrica de Belo Monte.

O movimento não apenas se ocupa da resistência à construção de novas barragens, mas denuncia as precárias condições de trabalho e o impacto socioambiental e econômico delas decorrentes. Ao mesmo tempo, opõe-se às reformas pretendidas 
pelo governo (previdência social e terceirização do trabalho, por exemplo), à privatização de empresas públicas e aos privilégios concedidos a empresas privadas, além de protestar contra os aumentos nas tarifas de energia elétrica. Além disso, está comprometido com a alimentação saudável (produção agroecológica). Acompanha os desdobramentos da investigação sobre o crime ambiental da Samarco, em Mariana/MG; invade prédios ou escritórios de entidades públicas, como o Ibama, assumindo como lema "água e energia não são mercadorias".

O MAB está organizado em dezesseis estados brasileiros e tem parceiros importantes, como o laboratório Estado, Trabalho, Território e Natureza (Ettern), do Instituto de Pesquisa e Planejamento Urbano e Regional (Ippur), da Universidade Federal do Rio de Janeiro (UFRJ), que desenvolveu o Observatório Socioambiental de Barragens ${ }^{3}$, com um banco de dados on line que "registra, organiza e disponibiliza informações sobre o setor elétrico brasileiro e, em particular, sobre barragens e aproveitamentos hidrelétricos", conforme se pode conferir no portal do MAB (www.mabnacional.org.br).

A dinâmica de atuação do MAB está alicerçada em um competente trabalho de comunicação, com a utilização de canais e estratégias para não apenas dar maior visibilidade às suas lutas e reivindicações, mas também favorecer a mobilização, 0 engajamento e o desenvolvimento de ações por parte de seus membros.

O portal do MAB sintetiza todo esse esforço comunicacional e se constitui em um espaço significativo para o acompanhamento do movimento e para a repercussão de suas conquistas e seus desafios. Ele traz notícias atualizadas sobre um amplo espectro de temas vinculados à questão socioambiental, com ênfase à temática das barragens, mas também uma série de documentos e materiais que dão suporte ao processo de mobilização, como dados sobre barragens, água, energia; áudio de músicas identificadas com os objetivos do movimento; artigos, vídeos, fotos, publicações, teses e inclusive poesias de militantes, com vigoroso chamamento à luta popular. 0 portal disponibiliza também informações em inglês, o que amplia a repercussão internacional da sua atuação.

O MAB dispõe de uma assessoria de imprensa e está presente nas mídias sociais (Facebook ${ }^{4}$ e Twitter $^{5}$ ), com postagens atualizadas sobre o movimento e suas lutas, fartamente ilustradas por vídeos, depoimentos e denúncias de agressões, inclusive assassinatos, contra seus membros ou simpatizantes.

A comunicação do MAB não assume uma perspectiva verticalizante, ou seja, não é obrigatoriamente produzida por uma estrutura monolítica, profissionalizada, mas está fundamentada na contribuição coletiva, na participação dos seus representantes ou membros, o que favorece o aumento da sua capilaridade e da sua eficácia. Ela está reforçada, de maneira contundente, pela atuação dos seus líderes e membros locais, num amplo trabalho de comunicação interpessoal, face a face, em que se sobressaem o uso de palavras de ordem e a convocação permanente para a luta.

A força mobilizadora do seu aparato comunicacional pode ser facilmente avaliada pelo desenvolvimento de ações concretas, como ocupação de áreas e prédios públicos, pressão direta junto à Justiça para prisão e condenação de pessoas e grupos que agrediram ou vitimaram seus membros, realização de encontros locais, regionais e nacionais e passeatas de protesto em diversas regiões do país, notadamente naquelas em que o movimento está organizado ou que abrigam hidroelétricas e, portanto, os diretamente atingidos pelas barragens.

3 Informações sobre o Observatório podem ser obtidas em <http://www.observabarragem.ippur.ufrj.br/>. 
A comunicação e a capacidade mobilizadora do MAB tem chamado a atenção até mesmo de estudiosos e pesquisadores nos campos da comunicação e das ciências sociais, que têm produzido trabalhos importantes sobre o seu potencial mobilizador. Além de Reis (2007), já citada, podemos mencionar Foschiera (2010), Vainer (2007, 2003) e o excelente trabalho de Locatelli (2014), sobre comunicação e barragens, que recebeu menção honrosa no Prêmio Capes de Tese, em 2012.

\section{Greenpeace e sua estratégia de "bom-mocismo" militante}

O Greenpeace é uma organização não-governamental com sede na Holanda, fundada em 1971, no Canadá, e que mantêm escritórios em dezenas de países, incluindo o Brasil. Seu foco é o meio ambiente em seu sentido mais abrangente, e suas ações e campanhas estão relacionadas a um leque amplo de temas, como a preservação do meio ambiente, a sustentabilidade, os transgênicos, a energia renovável, os oceanos, as mudanças climáticas, a poluição, entre muitos outros. Embora a organização indique explicitamente que não aceita recursos oriundos de empresas, partidos políticos e governos, sobrevivendo pela doação de ativistas ou simpatizantes (estimados em milhões em todo o mundo e cerca de 40 mil em nosso país), há denúncias de que acordos têm sido realizados com essas instâncias externas.

Essa entidade se caracteriza por ações espetaculares, mas não violentas, que, em muitos casos, promovem a desobediência civil, afrontando empresas e governos, com grande repercussão nos meios de comunicação. 0 grupo acumulou, ao longo de sua história, um conjunto importante e extenso de conquistas, dentre as quais se destacam o fim dos testes nucleares no Alasca pelos Estados Unidos e no Oceano Pacifico pela França, a moratória da caça de baleias, a luta contra as usinas nucleares, os transgênicos e o uso de substâncias químicas tóxicas em produtos eletrônicos. Sua presença é recorrente em congressos internacionais atuando como fonte para os temas que caracterizam a sua atuação.

A comunicação do Greenpeace está apoiada em campanhas que, como ele mesmo diz, representam "um trabalho de

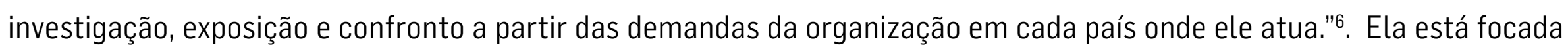
também no aumento do número de "colaboradores" (é assim que a ONG denomina aqueles que com ela contribuem) e agressivamente busca contatá-los, incentivando a adesão às suas campanhas e a divulgação das suas atividades.

O Greenpeace convida a todos, seus colaboradores ou não, a se tornarem ciberativistas, estimulando-os a "protestarem nas ruas da internet". Da mesma forma, ele favorece o voluntariado, convidando as pessoas a atuarem como "agentes de mudança". Nesse caso, 0 interessado precisa, obrigatoriamente, participar do "Greenwire"', mas há um rito a ser observado antes de ser aceito:

Ao entrar no Greenwire, você precisa assistir ao treinamento de boas-vindas e, em seguida, realizar um teste para mostrar que entendeu tudo sobre o trabalho voluntário no Greenpeace Brasil. Depois disso, você pode se juntar ao grupo local de sua cidade, criar um novo grupo, ou participar de mobilizações para as nossas campanhas (Greenpeace, s.d.).

0 grupo produz um número significativo de materiais de divulgação (vídeos publicitários, spots de rádio, anúncios, banners etc.) e empreende grande esforço no sentido de conseguir o apoio de veículos de comunicação e blogueiros para ampliar a sua divulgação. Ele mantém newsletter, blogue (Green blog), se vale de jogos e gadgets para conscientizar as pessoas e para divulgar os temas que constituem o foco de sua atenção. Pedagogicamente, instrui e capacita os interessados a se tornarem ativistas.

6 Cf. <http://www.greenpeace.org/brasil/pt/0-que-fazemos/>

7 Informações sobre como participar e como funciona o Greenwire podem ser encontradas em: <www.greenwire.org.br>. 
Essa vertente de comunicação do Greenpeace merece atenção especial e está explicitada em publicações (cartilhas, por exemplo) que ele mesmo denomina de "manuais de intervenção criativas", "dicas de comunicação" e "dicas de segurança". Nelas, ele evidencia a sua estratégia básica, com a utilização de "confrontos não violentos e criativos, mostrando que essa postura é uma alternativa eficaz para promover as mudanças que queremos ver no mundo".

O Greenpeace reconhece a importância das mídias sociais, da imprensa, das rádios livres, do uso de fotos e vídeos, notadamente para registrar e divulgar as suas "campanhas" ou manifestações, e instrui os que delas participam para evitar confrontos com a polícia ou adversários, para manter sigilo sobre as suas rotas e estratégias e tomar cuidado para evitar que os autores das informações (seus manifestantes) sejam identificados. Pede explicitamente o sigilo das informações e a proteção individual, sobretudo antes e durante as manifestações. Recomenda: "utilizar sistemas de encriptação de mensagens, no caso de e-mails; utilizar celulares pré-pagos para evitar que rastreamentos levam ao seu nome; utilizar aplicativos que sejam mais difíceis de serem rastreados; colocar senha no seu celular; e, se tiver registrando imagens com câmera fotográfica (e não celular), leve um cartão de memória falso ou vazio para entregar caso tentem confiscar suas fotos" (Greenpeace, Segurança da informação, s.d.)

A entidade também se vale da capilaridade propiciada pelas mídias sociais para promover a sua "luta digital", convicta de que o sucesso de sua mobilização depende, fundamentalmente, desses espaços virtuais, utilizados sobretudo para a troca de informações, a interação entre os seus colaboradores e voluntários e mesmo para "comunicar e registrar fatos antes, durante e depois das manifestações". As mídias sociais, especialmente o Facebook, o Twitter e o Tumblr, são considerados instrumentos estratégicos para a adesão às campanhas.

0 grupo valoriza bastante o relacionamento com a imprensa, ainda que admita que os meios de comunicação tradicionais sejam "comumente criticados por defender e propagar o discurso hegemônico das elites e distorcer/ocultar as demandas das minorias". Por isso, ele tem como objetivo fazer com que mensagens contra-hegemônicas sejam transmitidas em larga escala (e sem manipulações) pela imprensa tradicional", reconhecendo que ela "ainda tem seus produtos consumidos de maneira massiva pela maior parte da população, sendo ainda responsável por pautar a agenda de temas discutidos na sociedade e o viés com que esses temas serão abordados"8.

É possível perceber que o discurso utilizado pelo Greenpeace para a comunicação com os seus colaboradores e voluntários tem como característica básica um tom professoral, o que significa que, na prática, ele assume uma relação verticalizada com seus públicos, esperando deles mais a adesão do que a discussão de estratégias, definidas por ele a priori. O Greenpeace (e isso fica evidente no esforço utilizado para angariar assinaturas para as suas campanhas) imagina que colaboradores e voluntários sejam apenas seguidores, aos quais é permitida, e até mesmo incentivada, a conversa, mas não o questionamento de suas posições. Os colaboradores e voluntários não decidem sobre as suas práticas, apenas obedecem às determinações emanadas pelos dirigentes e gestores do Greenpeace. Katarini Miguel (2014, p. 196-197), ao analisar as estratégias discursivas do Greenpeace Brasil, chegou à mesma conclusão:

As petições para criação de projetos de lei, para exigir compromissos de empresas e governos são, aliás a forma de participação e ativismo mais direta, mas as reivindicações já estão prontas e só resta ao ciberativista assinar o documento e ter seu nome divulgado na página da web... Não há construção de propostas conjuntas, formas de colaborar com as informações disponibilizadas, nem mesmo mediação dos debates ou respostas diretas aos questionamentos realizados nas redes e no portal.

8 Ver informações e dicas sugeridas pelo Greenpeace para se relacionar com a imprensa no seguinte link: <http://greenpeace.org.br/p3/mobilizador/comunicacao/ color/af_imprensa140523.pdf>. 
Para a autora, prevalecem a "sloganização das problemáticas e a criação de pretensas marcas nas campanhas que servem para publicizá-las e atrair o sujeito de forma mais rápida, criativa e sem precisar de detalhamento", e a adoção de "modelo de discurso que evidencia um ethos combativo, militante, espetacular, que consegue adesão mais pelas estratégias midiáticas, inclusive pelos dispositivos virtuais utilizados, do que propriamente pela relevância da problemática ambiental" (Miguel, 2014, p. 198).

Comparativamente ao MAB, pode-se concluir que o Greenpeace promove a elitização das estratégias, das ações e dos discursos, um comportamento que evidencia um "bom-mocismo militante" que gera resultados, mas que se identifica mais com a desobediência civil e a irreverência nas ações comunicacionais e na sua práxis do que com o confronto, e 0 enfrentamento com o uso da força física.

\section{CONSIDERAÇÕES FINAIS}

A emancipação das organizações (associações, fundações, movimentos etc.) que constituem o terceiro setor passa, obrigatoriamente, pela autonomia na elaboração e execução de sua comunicação e pela adoção dos princípios básicos da participação e da corresponsabilidade.

A chamada comunicação comunitária, na acepção que utilizamos neste artigo, deve ser fruto de uma construção coletiva, de engajamento, de comprometimento, e contemplar, para sua efetivação, ações concretas de mobilização social. Para tanto, deve lançar mão de veículos ou canais e discursos que sirvam não apenas para convocar os seus praticantes para uma práxis militante, mas também para legitimar as organizações junto aos seus membros e à opinião pública.

A independência em relação ao capital privado e ao poder público representa atributo fundamental da comunicação comunitária, porque, caso contrário, ela pode tornar-se refém de interesses políticos e empresariais e induzir a parcerias que, em médio e longo prazos, acabam desconstruindo as suas identidades e iniciativas.

A vigilância cívica deve ser permanente e ela significa disposição para enfrentar resistências, coragem para superar lobbies e ameaças, competência para realizar ações bem-sucedidas e criatividade para contornar os desafios e propor estratégias, notadamente as no campo da comunicação.

Vigorosa e agressiva, como a comunicação do MAB, pedagógica e midiática, como a comunicação do Greenpeace, a comunicação comunitária autêntica deve favorecer a mobilização social tendo em vista a promoção de mudanças estruturais na sociedade para a superação das desigualdades e da injustiça social.

\section{REFERÊNCIAS}

FOSCHIERA, Atamis Antônio. A luta dos atingidos por barragens no Brasil: o caso dos atingidos pela usina hidrelétrica de Barra Grande. In: SIMPÓSIO LUTAS SOCIAIS NA AMÉRICA LATINA, IV, Londrina, Gepal, 14 a 17/09/2010. Anais..., p. $42-51$. Disponível em: <http://www.uel.br/grupo-pesquisa/gepal/anais_ivsimp/gt1/5_atamisfoschiera.pdf. Acesso em 10/03/2017>.

GREENPEACE. Cuidados e dicas ao falar com a imprensa tradicional. Disponível em: <http://greenpeace.org.br/p3/ mobilizador/comunicacao/color/af_imprensa140523.pdf>. Acesso em: 21/03/2017.

Segurança da informação. (s.d.). Disponível em: <http://greenpeace.org.br/p3/mobilizador/seguranca/color/af_ informacao_140527.pdf?_hstc=218051913.3a3385c439c59741cd7fe3c068295c46.1489155605713.1489155605713.1490546356508.2\&_ hssc $=218051913.16 .1490546356508 \& \_h s f p=2053031526>$. Acesso em: 23/03/2017. 


\section{ANO 14 • NÚMERO 26 • 1은. 2017 • ORGANICOM \\ COMUNICAÇÃO, MOBILIZAÇÃO SOCIAL E CIDADANIA: APRENDENDO COM A VIGILÂNCIA CÍVICA DO TERCEIRO SETOR}

Bem-vindo ao Greenwire: um lugar para agente de mudanças! Disponível em: <https://greenwire.greenpeace.org/ brazil/pt-br/>. Acesso em: 21/03/2017.

HENRIQUES, Márcio Simeone; BRAGA, Clara Soares; MAFRA, Rennan Lanna Martins. Planejamento da comunicação para a mobilização social: em busca da corresponsabilidade. 2003. Disponível em: <http://www.sinprorp.org.br/clipping/2003/ os\%20desafios.pdf>. Acesso em: 20/03/2017.

INSTITUTO PRO BONO. Manual do terceiro setor. São Paulo, s.d. Disponível em: <http://www.probono.org.br/arquivos/file/ manualterceirosetor.pdf>. Acesso em: 15/12/2016.

KUNSCH, Margarida M. Krohling. Planejamento e gestão das relações públicas comunitárias. In: KUNSCH, Margarida M. Krohling (Org.). Relações públicas: história, teorias e estratégias nas organizações contemporâneas. São Paulo: Saraiva, 2009. p.435-64.

LOCATELLI, Carlos. Comunicação e barragens: o poder de comunicação das organizações e da mídia na implantação de hidrelétricas. Florianópolis: Insular, 2014.

MIGUEL, Katarini Giroldo. Pensar a cibercultura ambientalista: comunicação, mobilização e as estratégias discursivas do Greenpeace Brasil. 263 fl. 2014. Tese (Doutorado em Comunicação Social) - Universidade Metodista de São Paulo.

PALÁCIOS, Marcos 0 medo do vazio: comunicação, socialidade e novas tribos. In: RUBIM, Antonio A. Canelas (Org.). Idade mídia. Salvador: UFBA, 2001.

PERUZZO, Cicília M. Krohling. Comunicação dos movimentos sociais: o exercício de uma nova perspectiva de direitos humanos. Contemporânea, Salvador, UFBA, v. 11, n. 1, p. 138-58, jan./abr. 2013.

Fundamentos teóricos das relações públicas e da comunicação organizacional no terceiro setor: perspectiva alternativa. Famecos, Porto Alegre, v. 20, n. 1, p. 89-107, jan./abr. 2013. Disponível em: <http://revistaseletronicas.pucrs.br/ ojs/index.php/ revistafamecos/article/view/13641/9201>. Acesso em: 23/12/2016.

PERUZZO, Cicília M. Krohling. Relações públicas nos movimentos sociais e nas "comuindades": princípios, estratégia e atividades. In: KUNSCH, Margarida M. Krohling (Org). Relações públicas: história, teorias e estratégias nas organizações contemporâneas. São Paulo: Saraiva, 2009. p. 417-34.

REIS, Maria José. 0 movimento dos atingidos por barragens: atores, estratégias de lutas e conquistas. In: SEMINÁRIO NACIONAL MOVIMENTOS SOCIAIS, PARTICIPAÇÃO E DEMOCRACIA II, Florianópolis, UFSC, 25 a 27/04/2007. Anais... UFSC, 2005, p. 473-501. Disponível em:< http://www.sociologia.ufsc.br/npms/maria_jose_reis.pdf. Acesso em 19/03/2017>.

VAINER, Carlos Bernardo. Recursos hidráulicos: questões sociais e ambientais. Estudos Avançados, São Paulo, USP, v. 21, n. 59, p. 119-37, 2007.

. Águas para a vida, não para a morte: notas para uma história dos atingidos por barragens no Brasil. In: ACSELRAD, Henri; HERCULANO, Selene; PÁDUA, José. Augusto (Orgs.). Justiça ambiental e cidadania. Rio de Janeiro: Relume Dumará, 2003. Disponível em: <file://C:/Users/Wilson\%20Bueno/Desktop/ Rela\%C3\%A7\%C3\%B5es\%20P\%C3\%BAblicas\%20 Comunit\%C3\%A1rias/\%C3\%81gua\%20para\%20a\%20vida,\%20de\%20Vainer.pdf>. Acesso em: 10/12/2016.

Texto recebido em 28.03.2017 e aprovado em 28.06.2017. 